\title{
Selective attention in children with reading disorders
}

\author{
Case \\ Report \\ Amani Mohamed El-Gharib ${ }^{1}$, Reham Mamdouh Lasheen ${ }^{1}$,Shereen Abohammar ${ }^{2}$ \\ ${ }^{1}$ ENT Department, ${ }^{2}$ Psychiatry Department, Faculty of Medicine, Tanta University, Egypt
}

\begin{abstract}
Objective: This work was designed to assess the selective attention in children with reading disorder (RD) using negative difference wave test $(\mathrm{Nd})$ or processing negativity $(\mathrm{PN})$ and Stroop test.

Design: The study included 40 children, divided into two groups; study group (SG) and control group (CG). SG consisted of 20 children with [RD]. CG consists of 20 normal children. All children were submitted to basic audiological evaluation, negative difference $(\mathrm{Nd})$ wave test and Stroop test.

Results: The reading disorder (RD) group showed delayed latency and decreased amplitude for both components of Nd. Results of Stroop test were significantly high among children with reading disorder compared with normal control.

Conclusion: In children with learning disability, selective attention is affected. Poor selective attention may contribute to poor letter and word recognition.
\end{abstract}

Key Words: Learning disorders (LD), reading disorder (RD), selective attention, stroop test, (Nd) wave test

Received: 14 December 2017, Accepted: 14 February 2018

Corresponding Author: Amani Mohamed El-Gharib, ENT Department, Faculty of Medicine, Tanta University, Tanta, Egypt, Tel.: 0403324203, E-mail: amanielgharib@yahoo.com

ISSN: 2090-0740, March 2018 Vol.19, No.1

\section{INTRODUCTION}

Learning disorders (LDs) are characterized by academic functioning that is substantially below that expected for the person's chronological age, measured intelligence and age-appropriate education. When the learning problem significantly interferes with academic achievement or daily activities that require basic academic skills such as reading, mathematical, or writing skills, a diagnosis of LDs is made ${ }^{[1]}$. A learning disorders is recognized by medical and mental health professionals as a neurobiological disorder of cognitive and/or language processing caused by atypical brain functioning ${ }^{[2]}$.

Among all learning disorders, reading disorders (RD) (also called specific reading disability or developmental dyslexia) have been the most thoroughly studied. It is perhaps the most common neurobehavioral disorder affecting children. Reading disorder is characterized by significant impairment in reading acquisition that does not have any demonstrable cause in vision, hearing, physical disorders, mental retardation, and emotional disturbance, environmental, cultural, or economic disadvantage ${ }^{[3]}$.

Attention is the cognitive process of selectively concentrating on one aspect of the environment while ignoring other things. Selective attention is a process crucial to the efficient processing of sensory information, and involves the selection and processing of relevant sensory information, while rejecting irrelevant information from further processing ${ }^{[4]}$. It is the key psychological ability related to learning and it is considered a preliminary step in memory processing ${ }^{[5]}$.

Selective attention has an important role in the reading process. Poor selective attention and inhibition may contribute to poor letter and word recognition. For instance, children with RD have to inhibit inadequate grapheme-phoneme correspondences (for instance reading ' $p$ ' as 'b' or ' $m$ ' as ' $n$ ' or 'nam' as 'man'). Failures to inhibit improper (though more dominant) pronunciations might impair word recognition performance in a more profound manner ${ }^{[6]}$.

Auditory selective attention can be indexed through the measurement of endogenous event-related potentials (ERPs) such as negative difference wave (Nd). It represents the difference wave of two auditory brain potentials during information processing. Nd induced when an auditory non target stimulus which is being heard in the attended channel elicits a larger cortical negativity than the same stimulus presented in the unattended channel ${ }^{[7]}$ The Negative difference wave $(\mathrm{Nd})$ was chosen as an appropriate parameter to assess frontal brain mechanisms of selective-attention ${ }^{[8]}$.

Nd represents the difference wave of two auditory brain potentials during information processing. Hymel et al. ${ }^{[9]}$ studied electrophysiologic signs of auditory competition in the human brain using $\mathrm{Nd}$ wave and reported that many researches indicated that the $\mathrm{Nd}$ wave 
reflects the presence of a separate endogenous attentional process, the 'processing negativity', rather than a gating or modulation of the exogenous components. So we used $\mathrm{Nd}$ wave test, as it may give more information as regards endogenous attentional mechanism than other tests used for assessing auditory selective attention.

Learning to read requires appropriate auditoryphonological and visual-spatial skills. This work was designed to study auditory and visual selective attention in $\mathrm{RD}$ children by studying negative difference wave test $(\mathrm{Nd})$ and Stroop test.

\section{SUBJECTS AND METHOD:}

\section{Subjects:}

This work was performed in the period between: November 2016 to April 2017. This study included 40 children were divided in to two groups, control group (CG) and study group (SG).CG consists of 20 normal children ( 10 male and 10 females). Their ages ranged from 9.1-12.9 years with the mean and SD of $10.94 \pm 1.09$. The control group was selected from the same schools and the same classes as they matched with sample regarding intelligence quotient and there was significant difference between them and study group as regard to the results of reading test which ensure good teaching programs in schools, and low scores of reading test reflects poor reading abilities of study group rather than poor teaching programs.

SG consisted of 20 children with reading disorders (12 males and 8 females). Their ages ranges from 9.1-12.4 years with the mean of $10.88 \pm 1.01$. All have normal hearing sensitivity.

\section{Exclusion criteria:}

-The presence of any neurological or psychiatric diseases.

-The use of drugs known to affect cognitive functions.

\section{All children in both groups were subjected to:}

1. Full history taking including: detailed personal and medical history.

2. Basic audiological evaluation: Standard pure tone audiometry using GSI version 61 audiometer (VIASYS. USA) for pure tone audiometry with headphone TDH 39, Acoustic immitance measurements (tympanometry/ stapedial reflex) by interacoustics AT235H impedance using low frequency $226 \mathrm{~Hz}$ probe tone (Denemark). Basic audiological evaluation was done to exclude any type or degree of hearing loss.

3. Nd wave test: elicited by Smart EPs of Intelligent hearing system using ER3A insert phone (IHS, Miami, USA).

\section{Electrode montage}

Four electrodes were used: one high frontal $\mathrm{Fz}$ (positive electrode), one low frontal Fpz (ground electrode) and two electrodes were placed on the left and right mastoids (as negative electrode or reference electrode).

\section{a- Recording parameters:}

The recording window was starting from -50 msec before stimulus onset to $409 \mathrm{msec}$ after stimulus presentation, giving a total time window of about 459 msec. The number of sweeps was 200 sweeps. The filter settings were $1 \mathrm{~Hz}$ to $30 \mathrm{~Hz}$.

\section{b-Stimulus parameters:}

Tone burst with frequencies of 500, $1000 \mathrm{~Hz}$. Each subject received $500 \mathrm{~Hz}$ tone-burst in one ear and the $1000 \mathrm{~Hz}$ in the other ear. The rise and fall time of the tone burst was $15 \mathrm{msec}$ with duration of $100 \mathrm{msec}$ (frequent stimuli, probability $40 \%$ ) or $175 \mathrm{msec}$ (infrequent stimuli, probability of occurrence $10 \%$ ). Repetition rate was 2.1 per second with stimulus intensity $70 \mathrm{~dB}$ $\mathrm{HL}$ and rarefaction polarity. The stimuli were presented binaurally starting with right ear. Every participant was instructed to attend to the longer duration tones (rare event) in particular ear and responded by raising his finger and counted the rare stimuli while ignoring the stimuli in the opposite ear.

\section{c-Measuring of Negative difference wave test ( $\mathrm{Nd}$ ):}

To investigate attention effects ( $\mathrm{Nd}$ wave), evoked potential waveforms recorded from ignore-frequent condition were subtracted from the response to the attendfrequent condition ${ }^{[9]}$.

\section{Psychiatric assessment includes the following:}

- Wechsler intelligence scale for children to measure IQ (WICS). Our sample was selected with IQ more than 90 .

- Using DSM5 criteria to diagnose learning disorder as follow:

\section{Specific Learning Disorder according to DSM V:}

\section{Diagnostic Criteria:}

A- Difficulties learning and using academic skills, as indicated by the presence of at least one of the following symptoms that have persisted for at least 6 months, despite the provision of interventions that target those difficulties:

1.Inaccurate or slow and effortful word reading (e.g., reads single words aloud incorrectly or slowly and hesitantly, frequently guesses words, has difficulty sounding out words). 
2.Difficulty understanding the meaning of what is read (e.g., may read text accurately but not understand the sequence, relationships, inferences, or deeper meanings of what is read).

3.Difficulties with spelling (e.g., may add, omit, or substitute vowels or consonants).

4.Difficulties with written expression (e.g., makes multiple grammatical or punctuation errors within sentences; employs poor paragraph organization; written expression of ideas lacks clarity).

5.Difficulties mastering number sense, number facts, or calculation (e.g., has poor understanding of numbers, their magnitude, and relationships; counts on fingers to add single-digit numbers instead of recalling the math fact as peers do; gets lost in the midst of arithmetic computation and may switch procedures).

6.Difficulties with mathematical reasoning (e.g., has severe difficulty applying mathematical concepts, facts, or procedures to solve quantitative problems).

B-The affected academic skills are substantially and quantifiably below those expected for the individual's chronological age, and cause significant interference with academic or occupational performance, or with activities of daily living, as confirmed by individually administered standardized achievement measures and comprehensive clinical assessment. For individuals age 17 years and older, a documented history of impairing learning difficulties may be substituted for the standardized assessment.

C-The learning difficulties begin during schoolage years but may not become fully manifest until the demands for those affected academic skills exceed the individual's limited capacities (e.g., as in timed tests, reading or writing lengthy complex reports for a tight deadline, excessively heavy academic loads).

D-The learning difficulties are not better accounted for by intellectual disabilities, uncorrected visual or auditory acuity, other mental or neurological disorders, psychosocial adversity, lack of proficiency in the language of academic instruction, or inadequate educational instruction.

Note: The four diagnostic criteria are to be met based on a clinical synthesis of the individual's history (developmental, medical, family, educational), school reports, and psychoeducational assessment.

Coding note: Specify all academic domains and sub skills that are impaired. When more than one domain is impaired, each one should be coded individually according to the following specifiers.

Specify if: 315.00 (F81.0) with impairment in reading

These criteria were applied by the examiner on the children attending child psychiatry outpatient clinic of
Tanta psychiatry and neurology center who referred for problem in reading by their teachers, after their diagnosis by the examiner according to previous criteria, the examiner referred them to the psychologist who was blind to the diagnosis of these children, who then apply the specific test of reading disorder.

-Specific Tests for reading disorder. It is diagnostic standardized test for reading which can be applied from age of 9 years ( $3^{\text {rd }}$ grade) to 12 years $\left(6^{\text {th }}\right.$ grade) as reading abilities develop in this age. RD is diagnosed when the results of the test below $85 \%$ of the total scores $(68.580 /)$, or when it is more than 2 standard deviation from normal test results.

\section{The test is composed of the following 4 dimensions:}

1-word recognition

2-word comprehension

3-sentences comprehension

4-paragraphs for silent reading

The test is composed of 80 sentences and each correct answer is given one degree and. The child was considered to have reading disorder when the result of the test was below $85 \%$ of the total score ${ }^{[10]}$.

The specific test for reading disorder which was designed and applied on a sample of Egyptian children showed test-retest reliability as the correlation coefficient indicated that stability of the scores that was 0.74 which was significant, the test also showed internal consistency that the correlation coefficient was 0,29 and 0.74 which was also significant.

The validity of the test was measured by correlation of the test results with children grades at end year exam in Arabic language which is their mother language, the correlation coefficient was 0,86 and 0.81 which was high and positively correlated.

\section{Stroop test:}

It was used to assess selective attention ${ }^{[1]}$. The version that will be used in this study is the computerized version of Stroop in (PEBL) Victoria-Stroop Task, Version 1.0 which is computerized Stroop Task. In the first part the participant must name the color of dots as quickly as he can press keys $(1,2,3$, and 4) which corresponding colors (green, blue, red and yellow). Then the participant is asked to name the color of the words as quickly as he can by pressing the correct key $(1,2,3,4)$. Then the participant is asked to name the color in which the word is printed but do not read the word itself ${ }^{[12]}$.Stroop test was used for assessment of selective attention through measuring Interference score for time (IS time): $\mathrm{C} / \mathrm{W}$ is calculated by dividing the time needed to read the color of the word (C) by the time needed to read the word (W), when the child needs more time to read the color of the 
word, the interference score was high which reflects poor interference control component of inhibition.

\section{Compliance with Ethical Standards:}

Every participant will have a code number. All children and their parents were thoroughly counseled about the procedure, stating the values, the hazards and the aim of the study. A written consent was obtained and signed by one of the parent of each participant.The study was approved by the institutional Ethics Committee of Tanta Faculty of Medicine, Egypt. Approval code of the research was is 31422 .

Any unexpected complication that will appear during the course of the research will be cleared to the participants and to the ethical committee on time.

Data were analyzed using Statistical Program for Social Science (SPSS) version 20. Quantitative data were expressed as mean \pm standard deviation (SD).

\section{RESULTS:}

There was no statistically significant difference as regard age and sex between two groups as $(p=0.49)$. There were no significant difference between the two groups regarding IQ measured WICS, as IQ in control group was $(90-109)$ with mean $(94.22 \pm 4.34)$ while IQ in reading disorder group was (90-101) with mean $(92.45 \pm 2.90)$.

As regards to Test for reading disorder, a child was considered to have reading disorder when the results of the test below $85 \%$ of the total score $(68.580 /)$, or when there is more than 2 standard deviation from normal test results.

\section{Nd results:}

Nd two negative components, early component (Nde) ranged from 100 to $140 \mathrm{msec}$ post stimulus, and late component (NdL) ranged from 250 to $350 \mathrm{msec}$. For both groups, there were no statistically significant differences between right and left ears as regards latency or amplitude of $\mathrm{Nd}$. So, both ears were considered as one group including 40 ears in the following tests. When we compared between Nde and NdL latency and amplitude between the two groups; using $\mathrm{T}$ test, there were statistically significant differences between the groups. The reading disorder (RD) group showed delayed latency and decreased amplitude for both components of Nd (Figure 1) (Table 1).

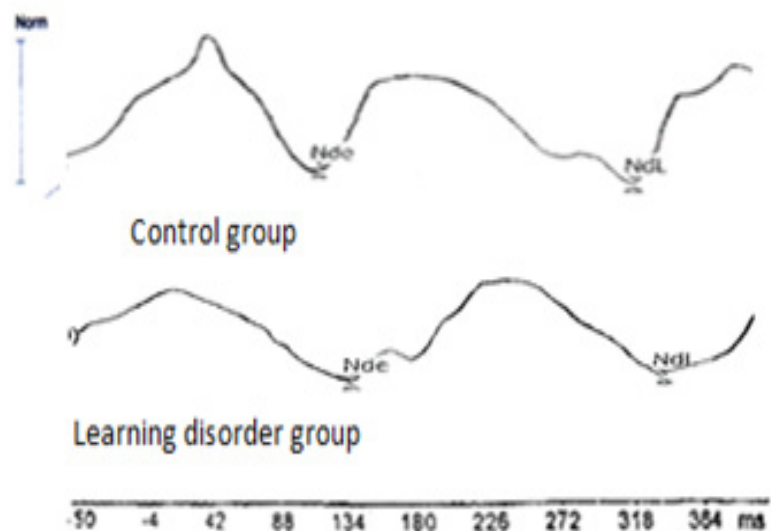

Fig.1: Nde and NdL in control and learning disorders

Table 1: Comparison between Nde and NdL latency (msec) and amplitude $(\mu \mathrm{sec})$ in the control group and reading disorder group

\begin{tabular}{|c|c|c|c|c|c|}
\hline & & Control & $\mathrm{RD}$ & T. test & P. value \\
\hline \multirow{2}{*}{ Nde Latency } & Range & $122-141$ & $136-155$ & \multirow{2}{*}{4.623} & \multirow{2}{*}{$0.001 *$} \\
\hline & Mean \pm SD & $133.24 \pm 10.63$ & $143.87 \pm 9.95$ & & \\
\hline \multirow[b]{2}{*}{ Ndl Latency } & Range & $302-337$ & $327-361$ & \multirow[b]{2}{*}{5.972} & \multirow[b]{2}{*}{$0.001 *$} \\
\hline & Mean $\pm \mathrm{SD}$ & $320.38 \pm 14.93$ & $338.58 \pm 12.21$ & & \\
\hline \multirow[b]{2}{*}{ Nde Amplitude } & Range & $2.14-2.51$ & $1.85-2.28$ & \multirow[b]{2}{*}{4.125} & \multirow[b]{2}{*}{$0.001 *$} \\
\hline & Mean $\pm \mathrm{SD}$ & $2.32 \pm 0.35$ & $2.02 \pm 0.42$ & & \\
\hline \multirow[b]{2}{*}{ Ndl Amplitude } & Range & $2.19-2.74$ & $1.91-2.51$ & \multirow[b]{2}{*}{2.834} & \multirow[b]{2}{*}{$0.006^{*}$} \\
\hline & Mean \pm SD & $2.51 \pm 0.41$ & $2.21 \pm 0.53$ & & \\
\hline
\end{tabular}

* Significant $P<0.05$ 


\section{Stroop test:}

IS time was significantly high among children with reading disorder compared with normal control as children with reading disorder had more (IS time) $(p<0.05)$ (Table 2).

Table 2: Comparison between Stroop color/word in the control group and reading disorder group

\begin{tabular}{lcccc}
\hline & Control & RD & T. test & P. value \\
\hline \multirow{2}{*}{ Stroop color / Word } & Range & $0.64-0.89$ & $0.75-0.99$ & \\
& & & 4.732 & $0.001^{*}$ \\
\hline
\end{tabular}

*Significant $P<0.05$

Correlation was done between latency and amplitude of both Nde and NdL and Stroop color/Word. There was negative correlation between Nde and NdL latency and Stroop color/Word. While, the correlation between Nde and NdL amplitude and Stroop color/Word was positive (Table 3).

Table 3: Correlation between Stroop color/word and both latency and amplitude of Nde and NdL

\begin{tabular}{lcc} 
& \multicolumn{2}{c}{ Stroop color / Word } \\
\cline { 2 - 3 } & $\mathrm{r}$ & $\mathrm{P}$ \\
\hline Nde Latency & -0.488 & $0.002^{*}$ \\
Ndl Latency & -0.450 & $0.004^{*}$ \\
Nde Amplitude & 0.736 & $0.001^{*}$ \\
Ndl Amplitude & 0.701 & $0.001^{*}$ \\
\hline
\end{tabular}

\section{DISCUSSION:}

In this study, $\mathrm{Nd}$ consisted of two negative components, early component (Nde) ranged from 100 to $140 \mathrm{msec}$ post stimulus, and late component ( $\mathrm{NdL}$ ) ranged from 250 to $350 \mathrm{msec}$. This results agreed with $^{[9,13]}$. In this work children with RD showed delayed latency and deceased amplitude for both components of Nd. These results indicated that auditory selective attention is affected in those children.

Affection in auditory selective attention was reported by Garcia et al. ${ }^{[14]}$. However, they used pediatric speech intelligibility test (PSI) with ipsilateral and contralateral competing message to assess auditory selective attention in children with learning disability not $\mathrm{Nd}$ test Taub et al. ${ }^{[15]}$ studied hearing-related selective attention processes in normal pre-school children, in children with learning disabilities and in children in which learning disabilities were suspected. Their results showed that auditory selective attention was affected in $90 \%$ of those children with learning disabilities ${ }^{[15]}$.

Stroop test was significantly impaired relative to control group in the three tested parameters of the test word, color and color/word index (W, C, C/W) as children with reading disorder toke more time in the test than the control group with high $\mathrm{C} / \mathrm{W}$ index which denoting that children with RD take more time to read the color of the word (C) than the time needed to read the name of the color $(\mathrm{W})$ which means selective attention deficit in RD group. These results referred to affection of visual selective attention in RD children.

The validity of the Stroop test as a measure of selective attention has been established in numerous research examining the effect of interference caused by an irrelevant stimulus attribute (i.e., the word attribute of the color-word for the color naming task ${ }^{[16]}$.

Our work was also in concordance with that of Morris et al. (2005) ${ }^{[17]}$ who had found impaired selective attention in Stroop test in children with RD. Our study was in concordance with many other sudies such as that of ${ }^{[18,19]}$.

From our results, we found selective attention affection in RD whether the task was auditory or visual. Besides, it also pointed to disorder in both visual and auditory selective attention and the greater the auditory affection and the greater the visual affection. These results suggest that a deficit of selective spatial attention may distort the development of phonological and orthographic representations that is essential for learning to read ${ }^{[20]}$.

From our results, we recommended that to improve RD ability to read specific training tailoring programs targeting not only visual selective attention but also auditory one may be used. 


\section{CONFLICT OF INTEREST}

There are no conflict of interest.

\section{REFERENCES}

1. Demonet JF, Taylor MJ, Chaix Y. Developmental dyslexia. Lancet.2004; 363:1451-60.

2. Dalen K, Bruaroy S, Wentzel-Larsen T, Nygaard M and Laegreid, LM. Non-verbal learning disabilities in children with infantile hydrocephalus, aged 4-7 years: A population-based, controlled study. Neuropediatrics.2006; 37: 1-5

3. Shaywitz S, Shaywitz B, Pugh K. The neuropsychology of dyslexia. In: Segalowitz S, Rapin I editors. Handbook of neuropsycholology. $2^{\text {nd }}$ ed. Vol 7 . Amsterdam: Elsevier.2009: 45-51.

4. Anderson JR. Attention and performance. In: Anderson JR (ed.). Cognitive psychology and its implications (6 $6^{\text {th }}$ ed.). Worth Publishers.2006: 63-91.

5. Medwetsky L. Mechanisms Underlying Central Auditory Processing. In: Katz J, Medwetsky L, Burkard R, Hood LG (eds.). Handbook of Clinical Audiology, $6^{\text {th }}$ edition. Lippincott Williams and Wilkins, Philadelphia. 2009: 584-610.

6. Schmid JM, Labuhn AS and Hasselhorn M. Response inhibition and its relationship to phonological processing in children with and without dyslexia. International Journal of Disability Development and Education.2011; 58:19-32.

7. Hillyard SA, Mangun CLR, Weldurff H. Neural systems mediating attention. In: Gazzaniga MS (ed.). The Cognitive Neurosciences.Cambridge, MIT Press, Boston, MA. 1995:665-681.

8. Rothenberger A, Banaschewski T, Heinrich H, Moll $\mathrm{GH}$, Schmidt MH, KloosterB. Comorbidity in ADHDchildren: effects of coexisting conduct disorder or tic disorder on event-related brain potentials in an auditory selective-attention task. Eur Arch Psychiatry ClinNeurosci.2000; 250:101-110.

9. Hymel M, Craford J, Carpenter M, Holbert D. Electrophysiological signs of auditory competition in the human brain. Neuroscience let. 2000; 283 (2): 105-108.
10. Nassra. Test of reading disability, Ph.D., unpublished thesis, educational psychology department, Faculty of education, Kafr El-Shekh University, Egypt.2005.

11. Stroop, J R. Studies of interference in serial verbal reactions. Journal of Experimental Psychology.1935; 18: 643-662.

12. Mueller ST. PEBL Experiment Tutorial How to write on exiperiment in PEBL. Meeting of The Cognitive Science Society, Boston, MA.http://pebl.sourceforge. net.2010.

13. El-Sawi H, El-Sanadeki H, El-Mahallawy T. Neuropsychologic And Audiologic Electrophysiological Findings In ADHD: AreAbnormal Event-Related Potentials Specific To Children With ADHD? A Comparison with Normal Children.Tanta Medical J. 2005; 33:1523-1532.

14. Garcia VL, Pereira LD, Fukuda Y. Selective attention psi performance in children with learning disabilities. Rev Bras Otorrinolaringol. 2007; 73(3):404-11.

15. Taub CF, Fine E, Cherry RS .Finding a link between selective auditory attention and reading problems in young children: a preliminary investigation.Perceptual and Motor Skills.1994; 78:1153-4.

16. MacLeod CM. Half a century of research on the Stroop effect: an integrative review. Psychological Bulletin.2001; 109:163-203.

17. Morris RD, Stuebing KK, Fletcher JM. Subtypes of reading disability: Variability around a phonological core. J Educ Psychol. 2005; 90:347-73

18. Lufi D, Cohen A, Parish-Plass J. Identifying attention deficit hyperactive disorder with the WISC-R and the Stroop color and word test. Psychology in the Schools. $2000 ; 27: 28-34$.

19. Harris EL, Schuerholz LJ, Singer HS, Reader MJ, Brown JE, Cox C, Mohr J, Chase CA, Denckla MB. Executive function in children with Tourette syndrome and/or attention deficit hyper-activity disorder. Journal of International Neuropsychological Society. 2005;1(6):511-6.

20. Facoettia A, Lorussoa ML, PaganonicP, Cattaneoa C, Galli R, UmiltaC, Mascetti GG. Auditory and visual automatic attention deficits in developmental dyslexia. Cognitive Brain Research. 2003;16: 185-191. 